
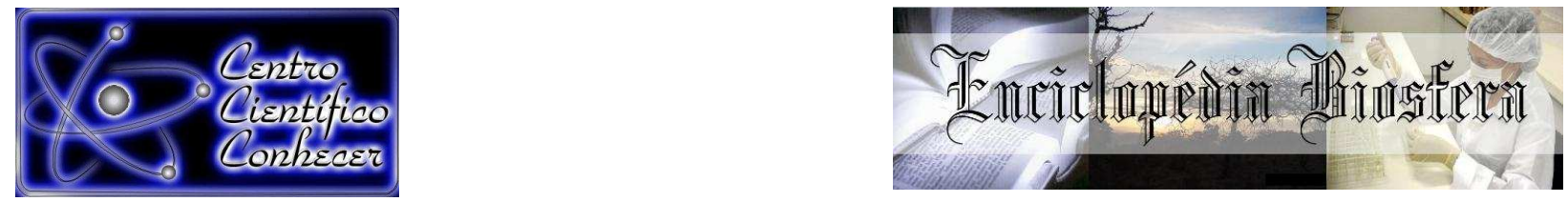

\title{
FARINHA DE CASCA DE MARACUJÁ: PRODUÇÃO E APLICAÇÃO NA ELABORAÇÃO DE COOKIES INTEGRAIS
}

Daniela Capelas Centeno ${ }^{1}$, Vidiany Aparecida Queiroz Santos ${ }^{2}$, Cássio Vinícius Martins ${ }^{3}$, Allan Hisashi Nakao ${ }^{4}$, Audenise Soares de Souza ${ }^{3}$

1. Graduanda em Agronegócios, Faculdade de Tecnologia do Estado de São Paulo, Jales, SP, Brasil. (danielacapelascenteno@hotmail.com).

2. Pós-doutoranda em Tecnologia de Processos Químicos e Bioquímicos,

Universidade Tecnológica Federal do Paraná. Pato Branco, PR, Brasil.

3. Graduandos em Agronegócios, Faculdade de Tecnologia do Estado de São

Paulo, Jales, SP, Brasil.

4. Doutorando em Sistema de Produção, Universidade Estadual Paulista "Júlio de Mesquita Filho", Ilha Solteira, SP, Brasil.

Recebido em: 08/09/2015 - Aprovado em: 14/11/2015 - Publicado em: 01/12/2015 DOI: http://dx.doi.org/10.18677/Enciclopedia_Biosfera_2015_264

\begin{abstract}
O Brasil é o maior produtor e consumidor mundial de maracujá-amarelo. Diariamente são produzidas toneladas de resíduos sólidos provenientes das agroindústrias, como cascas e sementes que possuem alto potencial econômico e nutricional. Assim, objetivou-se avaliar o aproveitamento de cascas de maracujá na elaboração da farinha e aplicá-la no processamento de cookies integrais sabor chocolate. Realizouse formulações com diferentes concentrações sendo, formulação 1 (controle) com $0 \%$ de adição de farinha de casca, formulação 2 com 25\%, formulação $3 \mathrm{com} 50 \%$ e formulação 4 com $75 \%$ de adição. Foi realizada a análise sensorial, baseada na escala hedônica de nove pontos, que foi de "desgostei muitíssimo" até "gostei muitíssimo". O uso da farinha de casca de maracujá é viável na elaboração de cookies integrais pois apresenta resultados promissores. A formulação 1 proporciona maior aceitação, entretanto quando adicionado a farinha da casca de maracujá, a formulação 2 obtém maior aceitação em todos os tributos. Necessita-se de trabalhos futuros para padronizar a melhor concentração a partir de valores próximos e/ou inferiores a $25 \%$ do produto.
\end{abstract}

RESUMO

PALAVRAS-CHAVE: maracujá-amarelo, resíduos sólidos orgânicos, análise sensorial.

\section{FLOUR OF PASSION FRUIT BARK: PRODUCTION AND APPLICATION IN WHOLE WHEAT COOKIES PREPARATION}

\begin{abstract}
The Brazil is the world's largest producer and consumer of yellow passion fruit. Daily are produced tons of solid residues of agro-industries, such as hulls and seeds that have high economic and nutritional potential. Thus, the objective of evaluating the use of passion fruit peels in the preparation of flour and apply it in the processing of integral cookies chocolate flavor. Formulations was performed with different concentrations, 1 formulation (control) with $0 \%$ added shell flour, 2 formulation with
\end{abstract}


$25 \%, 50 \%$ and 3 formulation with 4 formulation with $75 \%$ added. Sensory analysis, based on nine-point hedonic scale, which was "very much disliked" until "Seaview". The use of passion fruit shell flour is feasible in developing integral cookies because it presents promising results. 1 formulation provides greater acceptance, however when added to passion fruit Peel flour, 2 formulation gets greater acceptance in all the tributes. Needs further work to standardize the best concentration from values near $25 \%$ below the e/ou of the product.

KEYWORDS: passion fruit, organic solid waste, sensory analysis.

\section{INTRODUÇÃO}

O maracujá é originário de regiões tropicais e possui mais de 150 espécies nativas no Brasil. Dentre estas, as mais cultivadas são o maracujá-amarelo (Passiflora edulis f. flavicarpa), maracujá-roxo (Passiflora edulis Sims) e o maracujádoce (Passiflora alata Dryand).

O maracujá amarelo é uma planta de clima tropical com uma vasta distribuição geográfica, que por sua vez, encontrou no Brasil excelentes condições para seu cultivo (FILHO et al. 2010). No entanto o país é um dos maiores produtores mundiais de maracujá-amarelo, sendo que os frutos apresentam alta qualidade (ZERAIK et al., 2010).

A polpa do maracujá é rica em ferro, cálcio, fósforo, fibras e vitaminas $A$ e $C$, além de vitaminas do complexo B (OLIVEIRA et al., 2002). É uma fruta bastante apreciada pelo consumidor, e seu consumo se dá principalmente sob a forma de sucos, sorvetes e sobremesas (SANZONOWICZ \& JUNQUEIRA, 2005). Porém, os subprodutos como a casca raramente são empregados na alimentação humana, sendo descartada no ambiente ou utilizada para alimentação animal (MACAGNAN, 2013). Portanto, pesquisas de reaproveitamento de subprodutos de casca de maracujá são de grande valia, pois reportam a realidade da utilização como uma alternativa para a alimentação humana.

A casca de maracujá contém várias propriedades antioxidantes, nutricionais, e funcionais como a pectina, uma fibra solúvel que reduz a absorção de glicose na corrente sanguínea, combatendo assim a diabetes. Pode reduzir também o colesterol e auxiliar na perda de peso (HORN, 2014). Ressalta-se que tal farinha pode ser empregada na produção de biscoitos e cookies (ISHIMOTO et al., 2007).

Segundo FERRARI (2004), durante a extração de suco do Maracujá Amarelo, é gerada grande quantidade de resíduos. A fruta é composta por $23,2 \%$ de suco, $26,2 \%$ de sementes e $50,3 \%$ de casca, ou seja, $76,5 \%$ são resíduos sólidos. CÓRDOVA et al. (1999) afirmam que essa variedade é a mais utilizada para a fabricação de sucos, devido ao seu rendimento industrial.

Diante do exposto, objetivou-se produzir farinha de casca de maracujá e aplicar esta farinha no processamento de cookies integrais, com substituição parcial da farinha de trigo pela de casca de maracujá. E ainda, avaliar a aceitação sensorial e intenção de compra para as diferentes formulações estudadas.

\section{MATERIAL E MÉTODOS}

Para a realização desta pesquisa, foram selecionados aleatoriamente 50 provadores de ambos os gêneros, incluindo funcionários, estudantes e docentes da Faculdade de Tecnologia de Jales - FATEC Jales, que responderam um questionário composto por perguntas fechadas, pois de acordo com CRUZ \& 
RIBEIRO (2004), o questionário deve ser de fácil compreensão, por obter respostas com mais clareza, o que evita as incertezas.

\section{Matéria-prima}

Foram utilizadas cascas de maracujá-amarelo provenientes de uma miniindústria produtora de polpas de frutas congeladas, situada no município de JalesSP.

\section{Elaboração da farinha de casca de maracujá}

Conforme a Figura 1, as cascas de maracujá foram lavadas em água potável corrente e em seguida, foram imersas em solução sanitizante de hipoclorito de sódio durante 15 minutos. Após a sanitização, as cascas foram novamente enxaguadas em água corrente e então, foram cortadas com auxílio de faca de aço inoxidável em tiras de aproximadamente $1 \mathrm{~cm}$ de espessura. A seguir, as cascas foram imersas em solução de metabissulfito de sódio $2 \mathrm{ppm} / 15 \mathrm{~min}$.

Em seguida, as cascas de maracujá foram secas em estufa com circulação forçada de ar a $70 \stackrel{\circ}{ } \mathrm{C}$ durante 24 horas. Após a secagem, as cascas foram trituradas em multiprocessador industrial e em liquidificador até a obtenção da farinha na granulometria adequada. A farinha foi armazenada em potes com fechamento hermético, e estocados ao abrigo de luz e umidade até a utilização.

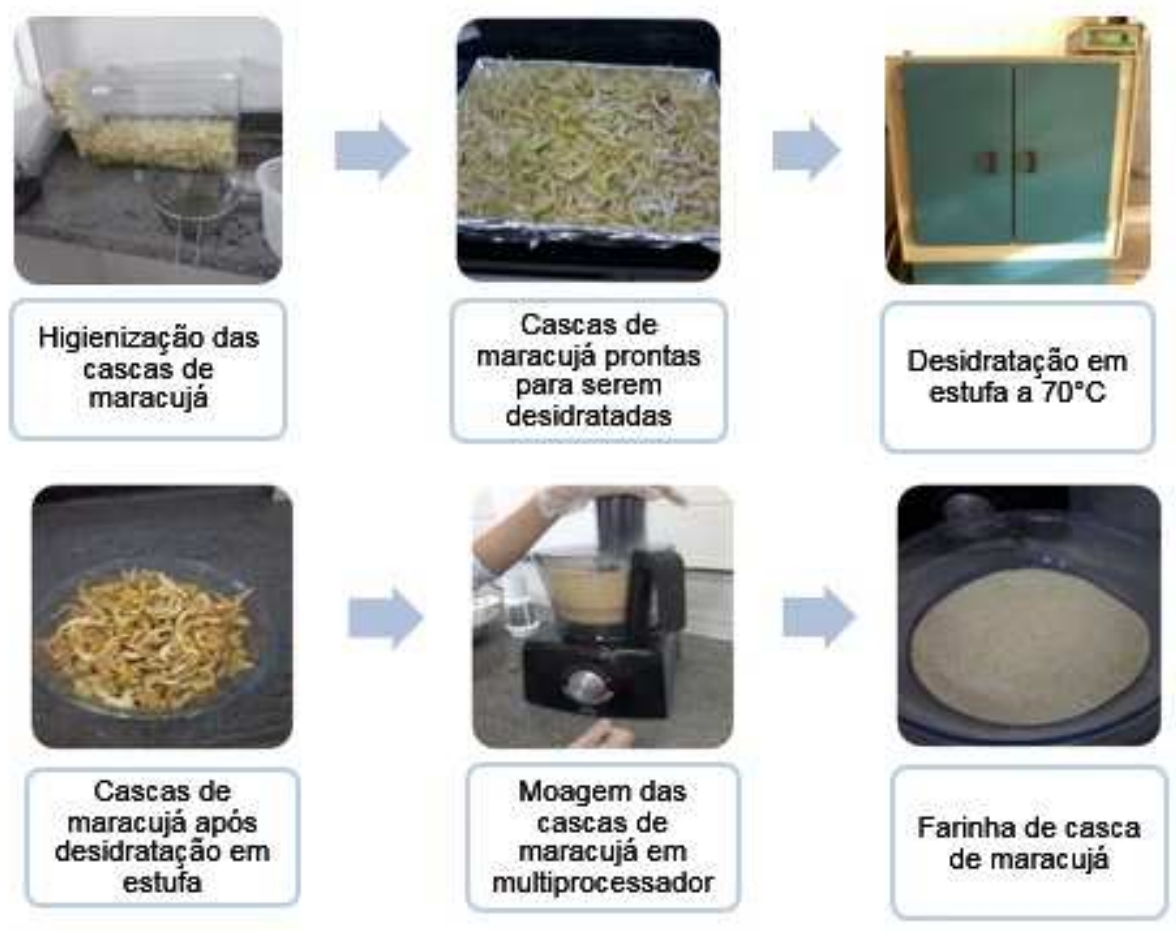

Figura 1. Fluxograma de elaboração da farinha de casca de maracujá.

\section{Elaboração dos cookies integrais adicionados de farinha de casca de maracujá}

Os cookies foram elaborados no laboratório de análise sensorial da FatecJales, adotando-se todas as precauções higiênico-sanitárias estabelecidas pela legislação vigente. Os cookies foram processados manualmente, e a formulação incluiu os seguintes ingredientes: farinha de trigo integral, farinha de trigo comum, margarina com sal, chocolate meio amargo (50\% cacau), açúcar mascavo, açúcar cristal, fermento químico e farinha de casca de maracujá (Tabela 1). Foram ENCICLOPÉDIA BIOSFERA, Centro Científico Conhecer - Goiânia, v.11 n.22; p. 37782015 
elaboradas formulações com diferentes concentrações de farinha de casca de maracujá, conforme a Tabela 2. O processo de elaboração e a aparência das formulações estão ilustrados na Figura 2.

Tabela 1 - Formulação padrão dos cookies integrais

\begin{tabular}{ll}
\hline Ingredientes & \\
\hline Ovo & $90 \mathrm{~mL}$ \\
Chocolate meio amargo & $150 \mathrm{~g}$ \\
Margarina com sal & $110 \mathrm{~g}$ \\
Farinha de trigo comum & conforme formulações (Tabela 2) \\
Farinha de trigo integral & conforme formulações (Tabela 2) \\
Farinha de casca de maracujá & conforme formulaçes (Tabela 2) \\
Açúcar mascavo & $100 \mathrm{~g}$ \\
Açúcar cristal & $60 \mathrm{~g}$ \\
Fermento químico & $15 \mathrm{~g}$ \\
\hline
\end{tabular}

Tabela 2 - Formulações dos cookies integrais com adição de farinha de casca de maracujá

\begin{tabular}{lcccc}
\hline & \multicolumn{4}{c}{ Formulações } \\
\hline Farinhas & 1 & 2 & 3 & 4 \\
\hline Farinha trigo comum & $100 \%$ & $50 \%$ & $25 \%$ & $25 \%$ \\
Farinha de trigo integral & - & $25 \%$ & $25 \%$ & - \\
Farinha de casca de maracujá & - & $25 \%$ & $50 \%$ & $75 \%$ \\
\hline
\end{tabular}
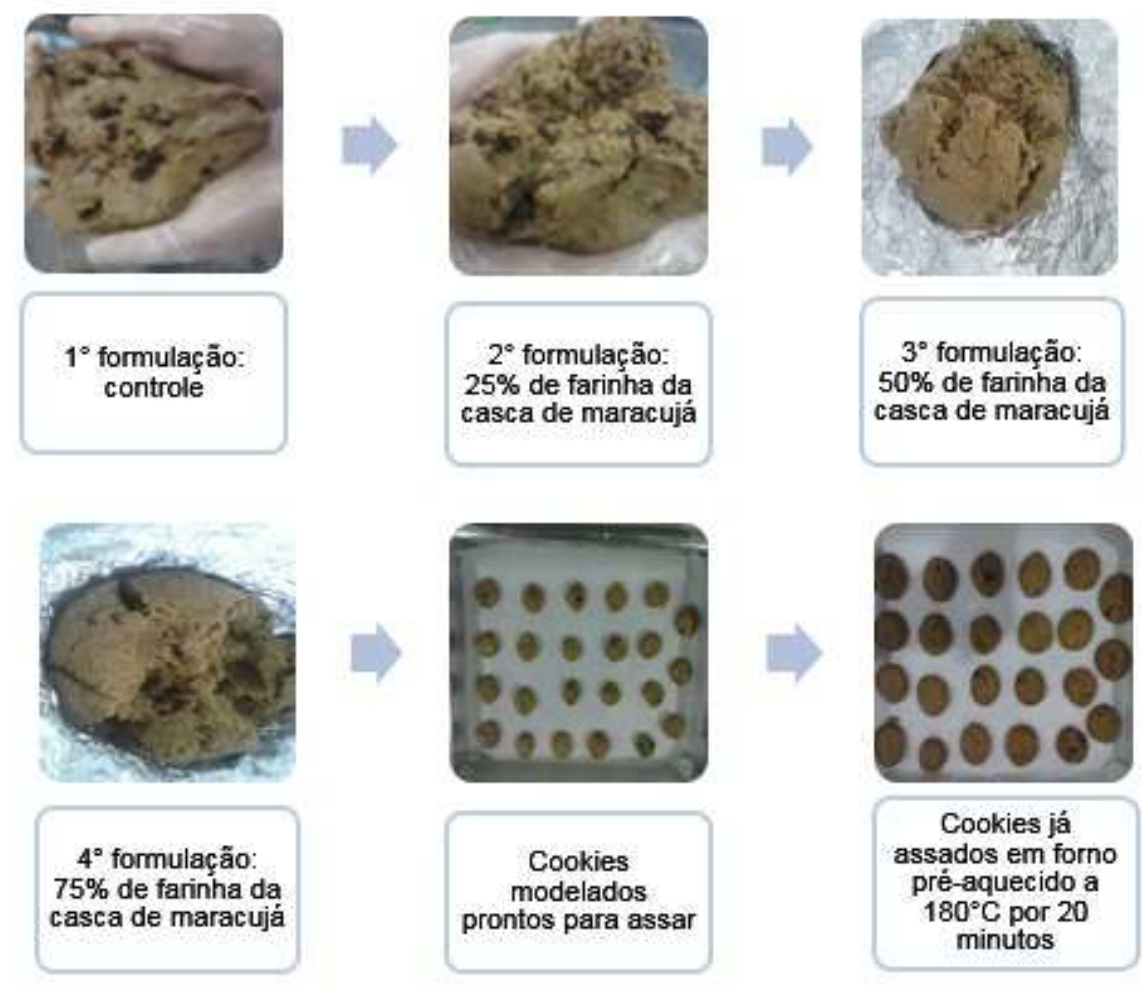

Figura 2. Fluxograma de processamento das quatro formulações de cookies integrais adicionados de farinha de casca de maracujá. 


\section{Análise Sensorial}

A análise sensorial foi realizada utilizando o teste afetivo a partir de uma escala hedônica de nove pontos, que vai de "desgostei muitíssimo" até "gostei muitíssimo" em relação aos atributos de aparência, sabor, aroma, textura e avaliação global. Foram utilizados consumidores de cookies como provadores não treinados, entre funcionários, estudantes e visitantes da instituição de ensino, totalizando 50 provadores para as diferentes formulações elaboradas.

As amostras, previamente codificadas com três números aleatórios, foram entregues aos provadores juntamente com a ficha de avaliação e um copo de água para a neutralização entre as amostras. As amostras foram apresentadas aos provadores de forma monádica e sequencial.

Os dados avaliados foram submetidos à estatística descritiva e análise de variância pelo teste $\mathrm{F}$ e as médias comparadas pelo teste de Tukey $(p<0,05)$.

\section{RESULTADOS E DISCUSSÃO}

\section{Caracterização do público alvo}

A população estudada apresentou maior número de indivíduos do gênero masculino $60 \%$, sendo $40 \%$ feminino. Isso reflete as modificações no perfil do consumidor atual, onde os homens tem apresentado maior interesse por alimentos benéficos à saúde.

Outro aspecto interessante é que $80 \%$ não são fumantes, indicando mais uma vez esta mudança para hábitos mais saudáveis. Em relação à faixa etária, a maioria $54 \%$ tem idade inferior a 20 anos, seguido de $20 \%$ entre 20 e 30 anos, $22 \%$ entre 30 a 50 anos e apenas $4 \%$ acima de 50 anos.

Quanto à escolaridade $52 \%$ tem ensino superior incompleto, $26 \%$ superior completo, $18 \%$ ensino médio completo, $2 \%$ médio incompleto e $2 \%$ ensino fundamental incompleto. O maior percentual para ensino superior reflete mais uma vez a população estudada, que inclui alunos e professores da faculdade de tecnologia de Jales.

Para avaliar preliminarmente a preferência dos provadores em relação aos cookies, estes foram questionados quanto a gostar ou não de cookies conforme demonstrado na Figura 3, $82 \%$ indicaram gostar muito ou moderadamente, $12 \%$ declararam-se indiferentes e $6 \%$ disseram gostar pouco do produto. Um dado interessante foi que nenhum entrevistado declarou não gostar de cookies. Estes resultados demonstram a grande afinidade da população avaliada pelo produto, 0 que foi muito importante porque o consumidor pôde avaliar com maior eficiência as diferentes formulações de cookies integrais adicionados com farinha de casca de maracujá. 


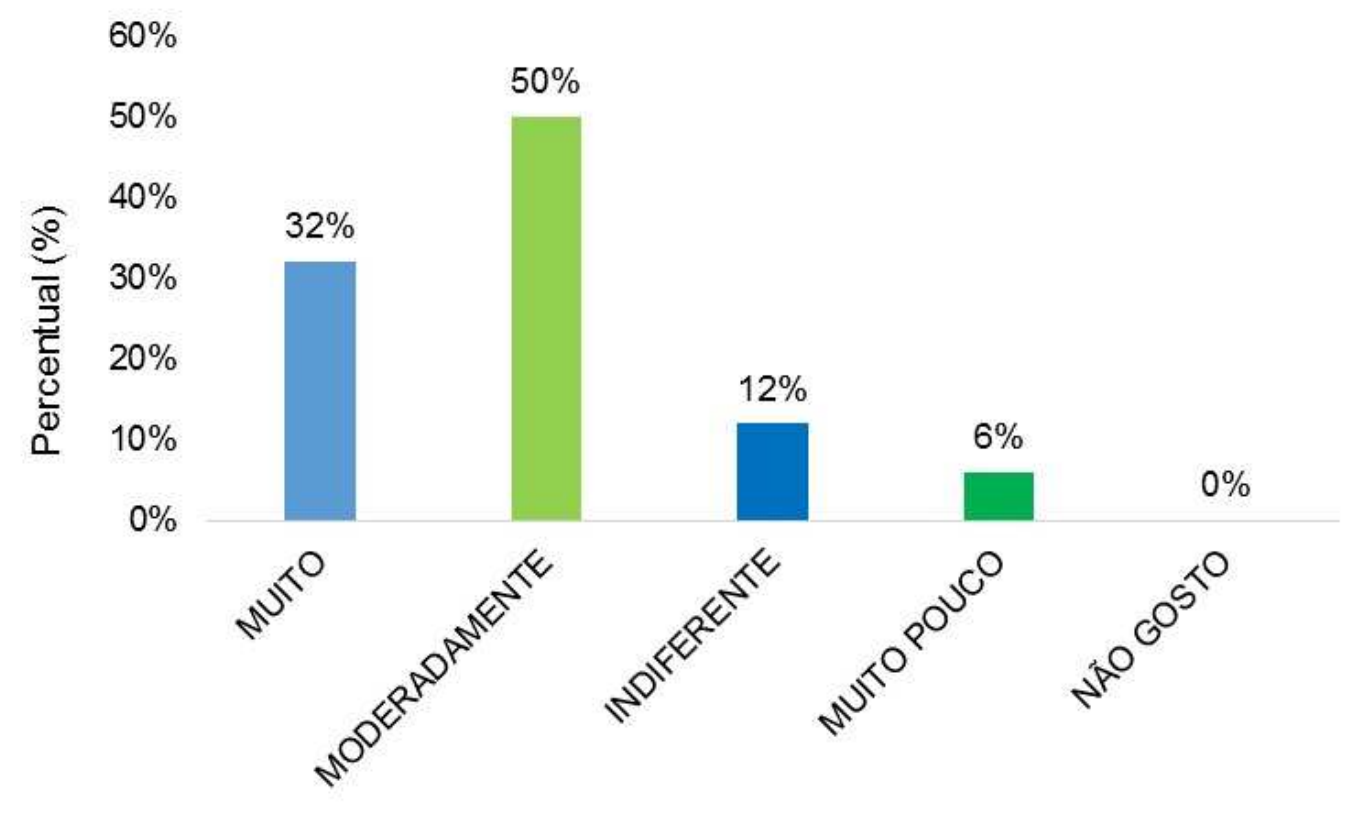

Figura 3. Opinião dos entrevistados quanto a gostar ou não de cookies.

Por outro lado, apesar da grande aceitação e afinidade do produto, os provadores demonstraram consumir pouco o produto, onde $2 \%$ disseram que não consomem e $22 \%$ consomem duas vezes por semana. Já os maiores percentuais foram observados para a frequência de consumo de 2 vezes por mês $(30 \%)$ e raramente $(44 \%)$. Por fim com menor porcentagem $(2 \%)$, foram aqueles que disseram consumir diariamente cookies, demonstrando assim baixo consumo. Este baixo percentual de consumo pode ser devido ao preço de venda e desconhecimento dos benefícios do produto, bem como pelo alto teor calórico que alguns tipos de cookies apresentam.

Conforme demonstrado na Figura 4, $70 \%$ dos entrevistados não tem conhecimento sobre os benefícios da farinha de casca de maracujá para a saúde, $28 \%$ conhecem pouco e apenas $2 \%$ declararam conhecer estes benefícios. Diante desta informação, verifica-se que apesar dos entrevistados terem afinidade pelo produto, a falta de conhecimento sobre seus benefícios pode afetar o consumo do produto. 


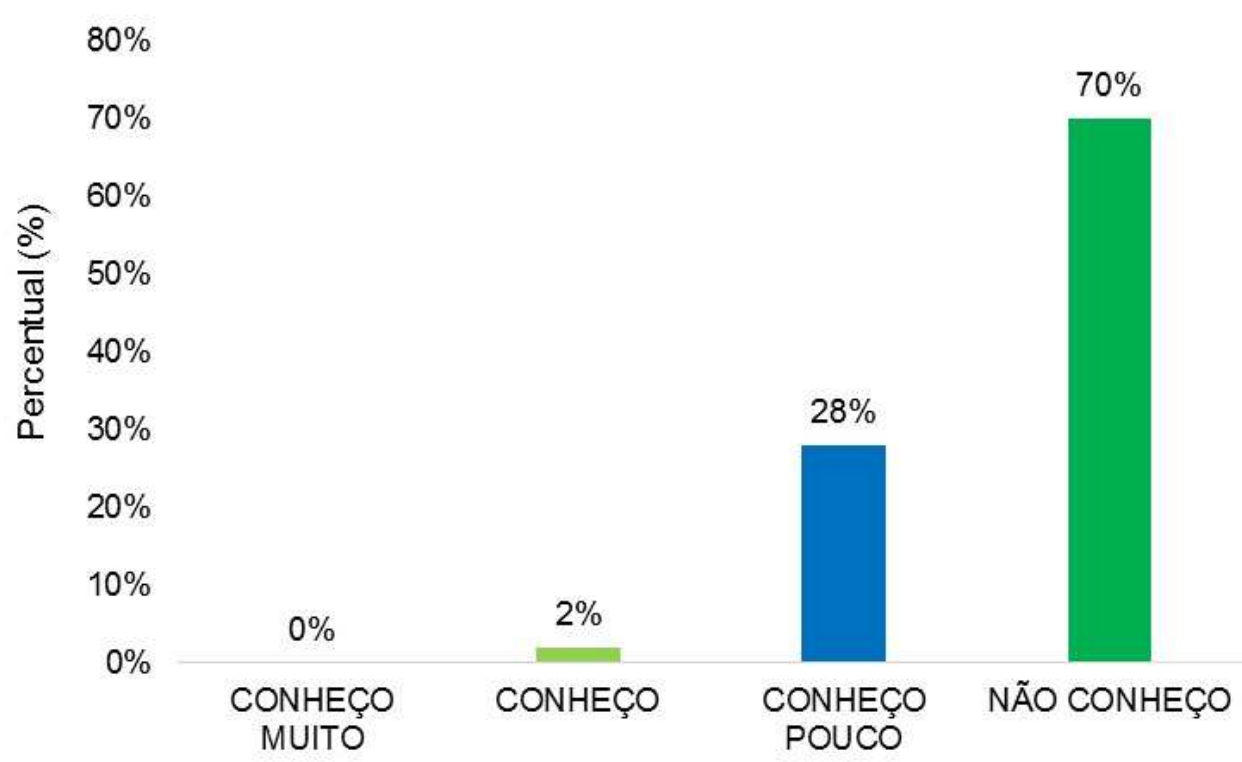

Figura 4. Opinião dos entrevistados quanto ao grau de conhecimento sobre os benefícios à saúde ocasionados pelo consumo de farinha de casca de maracujá.

Em relação aos atributos sensoriais, as formulações de cookies integrais de farinha de casca de maracujá apresentaram, de maneira geral, boa aceitação pelos avaliadores, com notas 5 a 7 , conforme demonstrado na Tabela 3.

\section{Avaliação sensorial das formulações de cookies integrais adicionados de farinha de casca de maracujá}

$\mathrm{Na}$ Tabela 3 estão apresentados os resultados para os diferentes atributos sensoriais avaliadas em função da farinha de casca de maracujá.

Para a avaliação global, verificou-se que todas as formulações adicionadas de farinha de casca de maracujá diferiram da formulação 1 (controle) pelo teste de Tukey (Tabela 3), evidenciando que o controle obteve melhores resultados.

Quanto ao sabor, para as diferentes formulações de cookies, verificou-se que as formulações 3 e 4 , apresentaram diferenças, em relação a formulação 1 (controle), conforme destacado na Tabela 3. A preferência por sabor encontra-se nos cookies sem a adição a farinha. Porém a formulação 2 não apresentou diferenças em relação ao controle, mostrando aceitabilidade dos consumidores quanto ao sabor. ISHIMOTO et al. (2007) destacam que biscoitos elaborados com substituição parcial de farinha de trigo pela farinha de casca de maracujá apresentaram 7,5 vezes mais fibras solúveis e insolúveis em sua constituição do que biscoitos comuns. Esta afirmação ressalta o aspecto saudável dos cookies elaborados neste estudo com adição de $25 \%$ de farinha de casca de maracujá.

Em relação à textura, as formulações 3 e 4 apresentaram diferença em relação a formulação $1(p<0,05)$, com resultados negativos, mostrando que a adição com farinha de maracujá não melhora a textura dos cookies avaliados. Para o aroma houve diferença entre a formulação 1 (controle) e as formulações 2, 3, e 4. Por outro lado, entre as formulações 2,3 , e 4 não houve diferença $(p>0,05)$. Para a variável aparência, não houve diferença em relação as formulações. 
Tabela 3. Tabela ANOVA para os valores médios dos atributos sensoriais nas diferentes amostras de cookies integrais adicionados de farinha de casca de maracujá.

\begin{tabular}{ccccc}
\hline Formulação & Sabor & Textura & Aroma & Aparência \\
\hline 1 & $7,72^{\mathrm{a}}$ & $7,14 \mathrm{a}$ & $7,32 \mathrm{a}$ & $6,84 \mathrm{a}$ \\
2 & $7,04 \mathrm{ab}$ & $6,62 \mathrm{ab}$ & $6,50 \mathrm{~b}$ & $6,34 \mathrm{a}$ \\
3 & $6,18 \mathrm{~b}$ & $6,18 \mathrm{bc}$ & $6,44 \mathrm{~b}$ & $6,66 \mathrm{a}$ \\
4 & $5,26 \mathrm{c}$ & $5,72 \mathrm{c}$ & $6,16 \mathrm{~b}$ & $6,58 \mathrm{a}$ \\
\hline Teste F & 19,40 & $11,45^{\star *}$ & $7,15^{\star *}$ & $1,09^{\text {ns }}$ \\
\hline CV $(\%)$ & 26,13 & 19,77 & 19,97 & 21,20 \\
\hline DMS & 0,88 & 0,65 & 0,68 & 0,72 \\
\hline
\end{tabular}

Médias na mesma coluna com letras diferentes diferem entre si conforme o Teste de Tukey.

$(p<0,05){ }^{* *} e^{*}$ : significativo ao nível de 1 e $5 \%$ respectivamente ns: não significativo. CV: coeficiente de variação; DMS: diferença mínima significativa.

De acordo com a Figura 5, a formulação 1 obteve maior aceitação representando $68 \%$ das notas entre 8 e 9 . Isto indica que os provadores declararam gostar extremamente e muitíssimo.

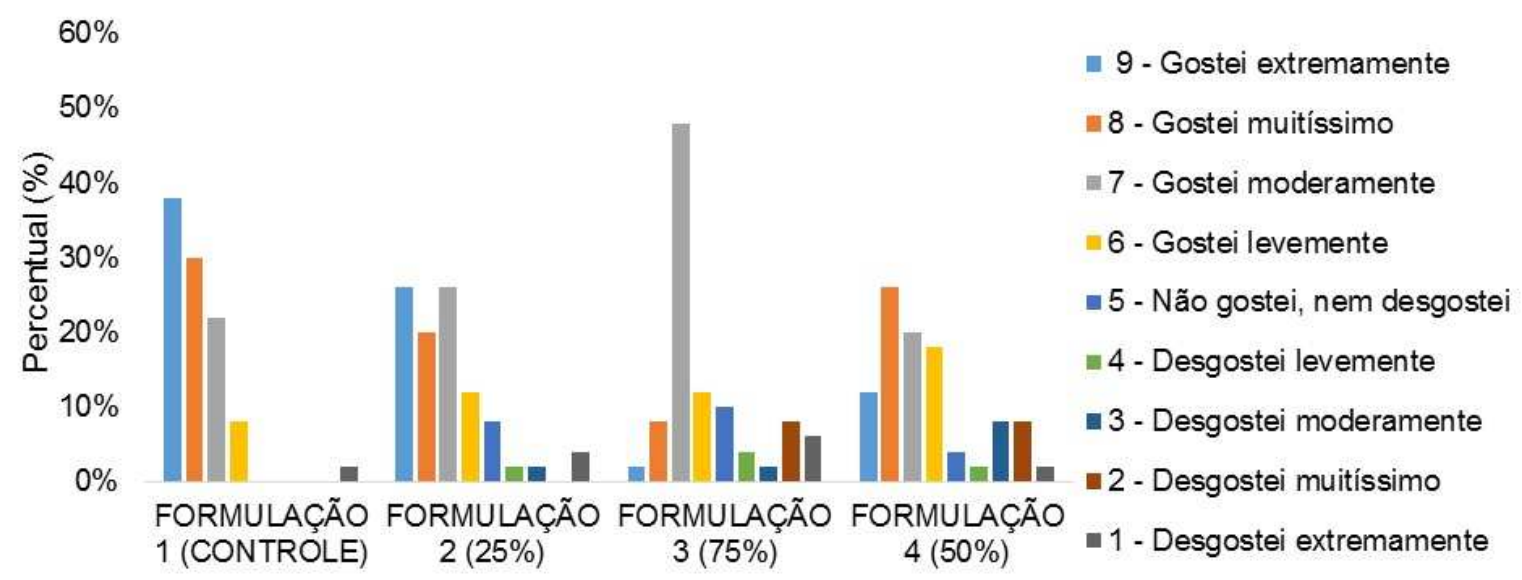

Figura 5. Opinião dos entrevistados quanto à avaliação global para as diferentes formulações de cookies integrais adicionados com farinha de casca de maracujá.

Conforme a Figura 6, a formulação 1 foi a que apresentou o maior percentual de avaliações positivas, somando $68 \%$ das respostas entre gostei extremamente e gostei muitíssimo, seguida da formulação $2 \mathrm{com} 48 \%$, a formulação $3 \mathrm{com} 34 \%$ e por último, a formulação 4 com apenas $16 \%$. 


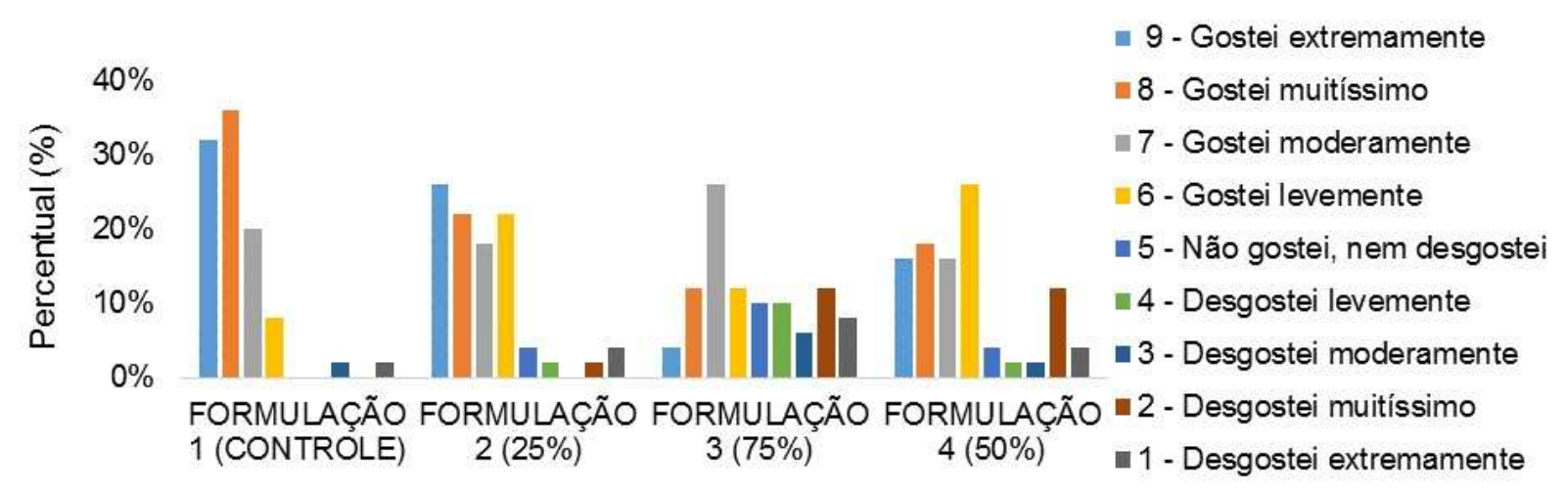

Figura 6. Opinião dos entrevistados quanto ao sabor para as diferentes formulações de cookies integrais adicionados com farinha de casca de maracujá.

A formulação 1 em relação a textura, assim como foi observado para o sabor apresentou maior aceitação, somando $46 \%$ das respostas entre gostei extremamente e gostei muitíssimo, seguida de $32 \%$ para gostei moderadamente e $12 \%$ gostei levemente. Por outro lado, $10 \%$ dos provadores consideraram esta formulação ruim, conforme destacado na Figura 7. A formulação 2 apresentou-se também com boa aceitação, somando $32 \%$ das respostas entre gostei extremamente e gostei muitíssimo, seguida de $36 \%$ para gostei moderadamente e $16 \%$ gostei levemente, porém $4 \%$ foram indiferentes e $12 \%$ não gostaram. As formulações 3 e 4 apresentaram os maiores percentuais para avaliação negativa das formulações, entre desgostei levemente e desgostei extremamente, com $16 \%$ para a formulação 3 e $24 \%$ para a formulação 4 . Quanto aos indiferentes $6 \%$ e $8 \%$ respectivamente. Tais formulações apresentaram em contrapartida, percentuais de gostei extremamente a gostei levemente de $78 \%$ da formulação 3 e $68 \%$ da formulação 4.

Já para SANTOS (2013), ao elaborarem cookies a base de farinha de casca de abóbora e albedo de maracujá, verificaram aceitação maior que $70 \%$ para todos os tratamentos avaliados em relação ao sabor, aroma e aparência, porém para a textura este comportamento não foi observado, onde alguns tratamentos não foram bem aceitos pelos provadores.

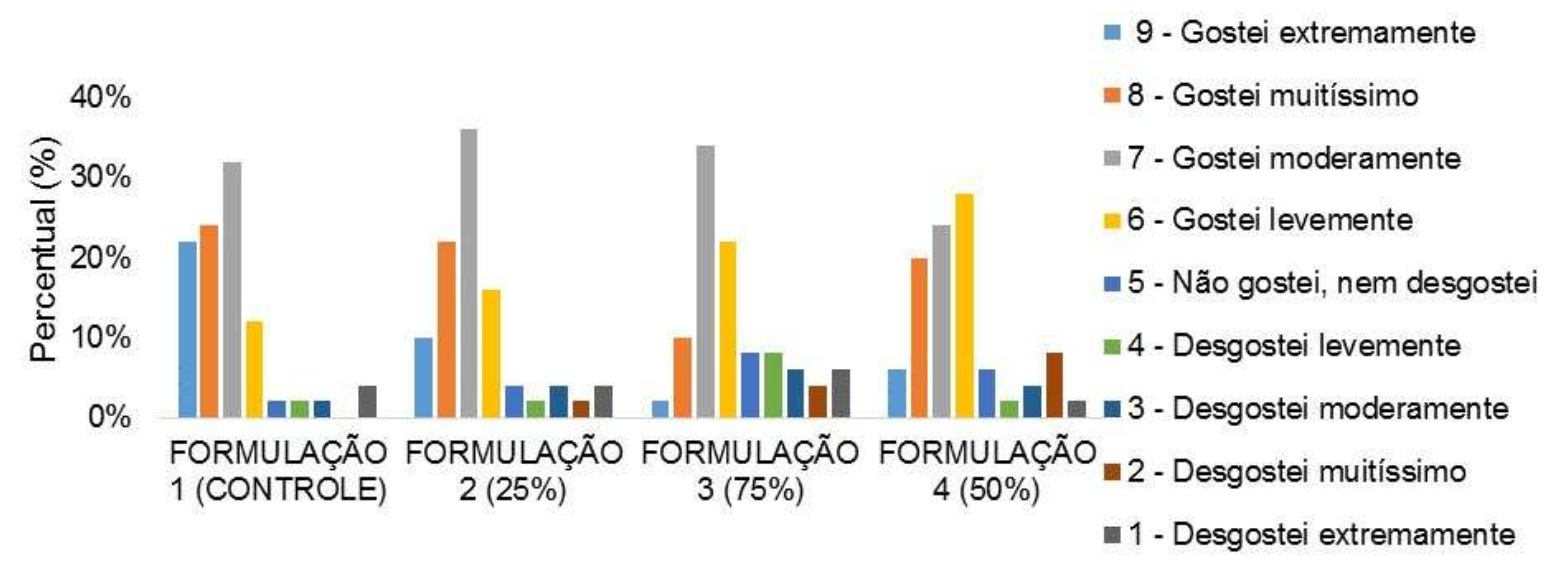

Figura 7. Opinião dos entrevistados quanto à textura para as diferentes formulações de cookies integrais adicionados de farinha de casca de maracujá. 
De acordo com a Figura 8, a formulação 1, mais uma vez apresentou maior percentual de aceitação pelo consumidor, somando $44 \%$ das avaliações entre gostei extremamente e muitíssimo, seguida de $50 \%$ de notas entre gostei levemente e moderadamente. Apenas $2 \%$ declararam ser indiferentes ou não gostaram e $4 \%$ acharam ruim. No entanto, a formulação 2 apresentou percentual significativo em relação as outras quando adicionado a farinha da casca, $40 \%$ gostaram levemente e moderadamente, seguido de $36 \%$ para muitíssimo e extremamente e ainda $12 \%$ declararam ser indiferente e $12 \%$ não gostaram do aroma da amostra. A formulação 3 apresentou percentual $50 \%$ para gostei levemente e moderadamente, seguido de $30 \%$ para muitíssimo e extremamente e ainda $4 \%$ declararam ser indiferente e $16 \%$ não gostaram do aroma da amostra. A formulação 4 apresentou $22 \%$ de avaliações entre gostei extremamente e muitíssimo e $54 \%$ para gostei levemente e moderadamente, $6 \%$ foram indiferentes e 18\% declararam não gostar do aroma da amostra, conforme figura 8 .

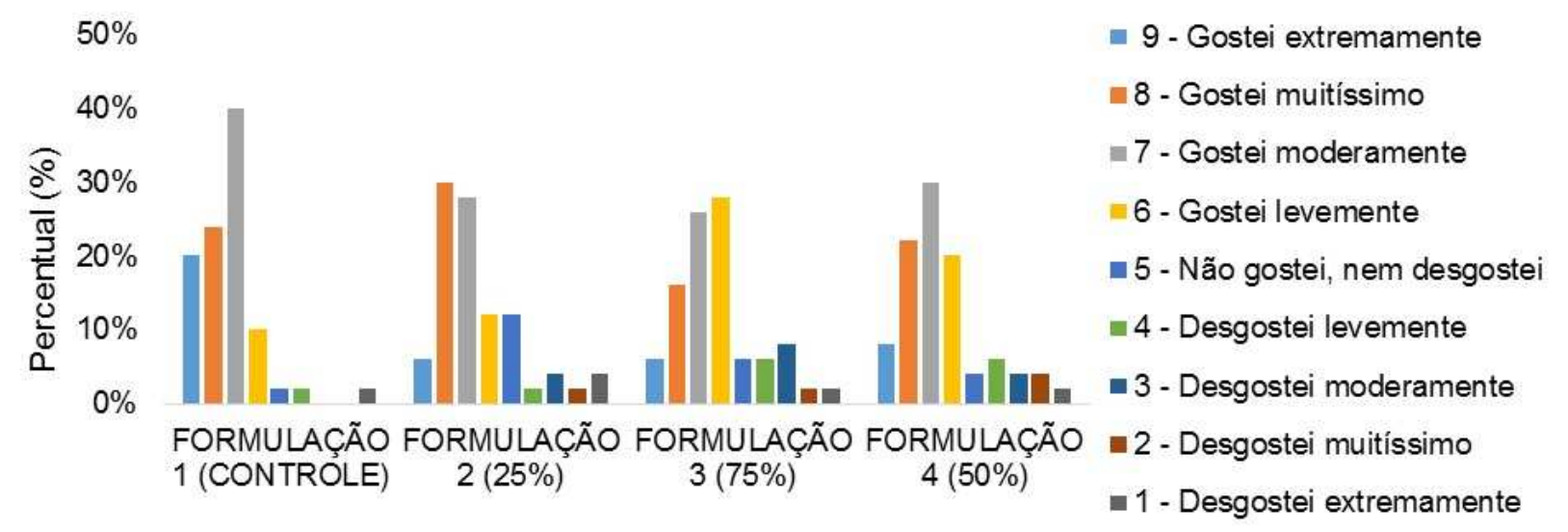

Figura 8. Opinião dos entrevistados quanto ao aroma para as diferentes formulações de cookies integrais adicionados de farinha de casca de maracujá.

Quanto a aparência de acordo com a Figura 9, as formulações 1 e 3 apresentaram boa aceitação com $48 \%$ e $40 \%$ para as avaliações entre gostei extremamente e muitíssimo, $34 \%$ e $40 \%$ entre gostei moderadamente e gostei levemente, $6 \%$ e $4 \%$ indiferente e $12 \%$ e $16 \%$ desgostei levemente e desgostei extremamente respectivamente. Já as formulações 2 e 4 não obtiveram boa aceitação, pois $32 \%$ e $32 \%$ para as avaliações entre gostei extremamente e muitíssimo, $48 \%$ e $46 \%$ entre gostei moderadamente e gostei levemente, $4 \%$ e $12 \%$ indiferente e $16 \%$ e $10 \%$ desgostei levemente e desgostei extremamente respectivamente. 


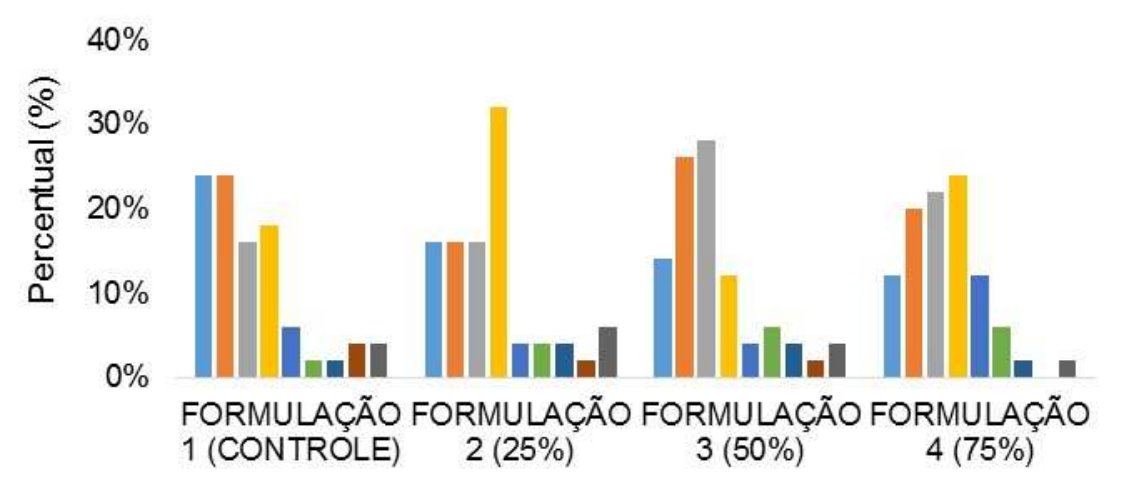

- 9 - Gostei extremamente

m 8 - Gostei muitíssimo

7 - Gostei moderamente

=6 - Gostei levemente

- 5 - Não gostei, nem desgostei

4 - Desgostei levemente

n 3 - Desgostei moderamente

= 2 - Desgostei muitíssimo

1 - Desgostei extremamente

Figura 9. Opinião dos entrevistados quanto a aparência para as diferentes formulações de cookies integrais adicionados de farinha de casca de maracujá.

De maneira geral a formulação 1 foi a mais aceitável pelos provadores, pois possui menor quantidade de farinha de casca de maracujá o que a torna mais palatável. Porém vale destacar que quando adicionada a farinha da casca de maracujá, a formulação 2 comparada com a formulação 1 (controle), apresentou maiores percentuais, evidenciando uma diminuição no trigo e adição de $25 \%$ de farinha da casca de maracujá. Nas figuras de 4 a 9 verifica-se também que houve altos percentuais de rejeição, principalmente para as formulações 3 e 4, porém isso não influenciou na intenção do consumidor que gostou do produto em ter intenção de consumi-lo, como é demonstrado na Figura 10. Nesta figura destaca-se a intenção de compra da formulação de maior preferência pelo provador, indicando que $50 \%$ certamente comprariam e $42 \%$ provavelmente comprariam. Por outro lado, apenas $10 \%$ não tinham certeza ou provavelmente não compraria a formulação.

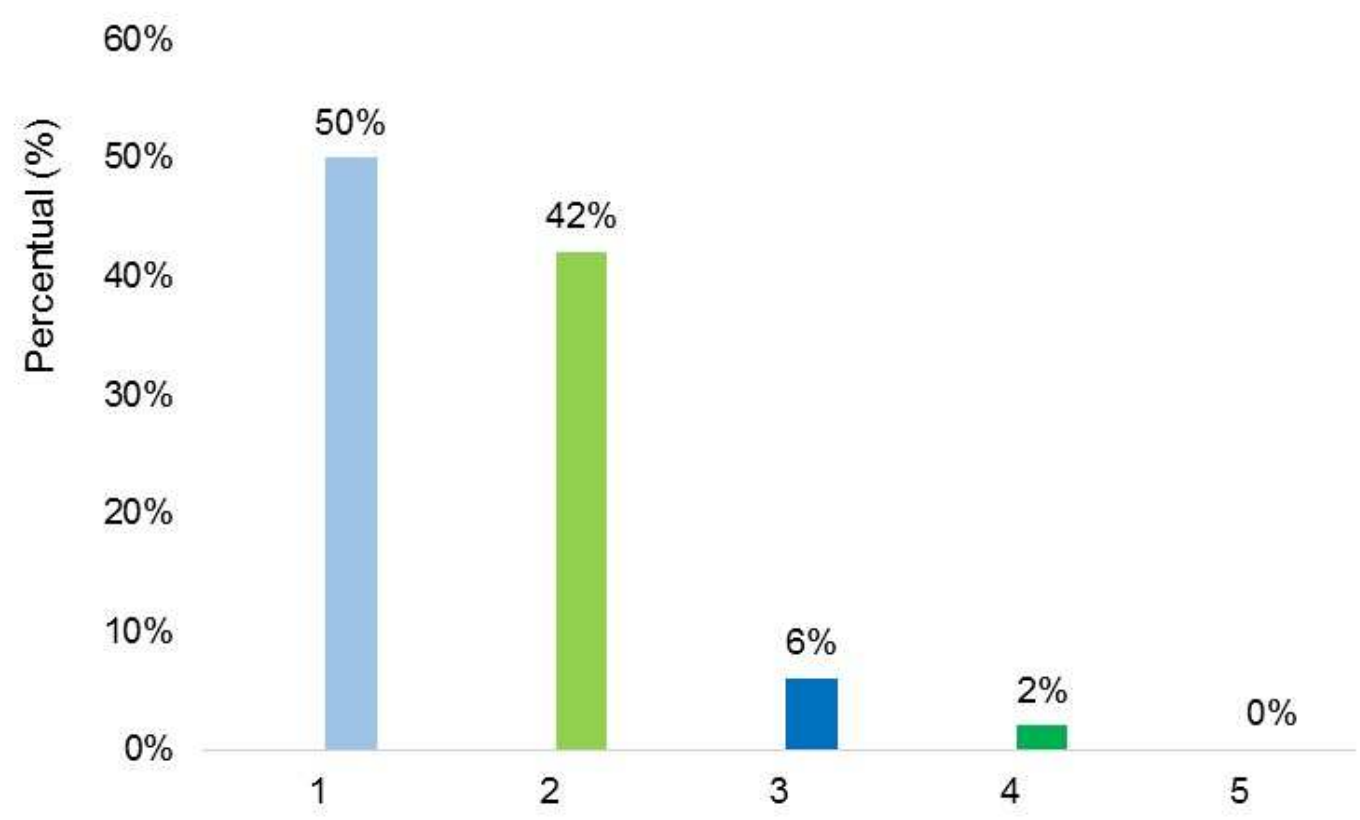

Figura 10. Opinião dos entrevistados quanto a intenção de compra da amostra de maior preferência. Em que: 1- Eu certamente compraria esta amostra; 2- Eu provavelmente compraria esta amostra; 3- Tenho dúvidas se compraria esta amostra; 4- Eu provavelmente não compraria esta amostra; 5- Eu certamente não compraria esta amostra. 
ANDO et al. (2007) também avaliaram a substituição de farinha de trigo por farinha da casca de maracujá na produção de cookies e observaram que quanto menor a concentração de farinha da casca de maracujá substituída, maior a aceitação pelos provadores. Este comportamento também foi observado neste estudo, uma vez que a formulação 2 , foi a única com $70 \%$ de aceitação para sabor e aceitação global. (Tabela 3). É importante destacar, no entanto, que este autor utilizou concentração máxima de $20 \%$ de farinha de casca de maracujá, ou seja, muito inferior a utilizada neste estudo, e mesmo assim houve redução na aceitabilidade do produto para o sabor. Esta informação ressalta que os resultados obtidos neste estudo são semelhantes, pois a medida que houve aumento da porcentagem de farinha de casca de maracujá houve redução da aceitabilidade dos provadores.

Por outro lado, AMARAL et al. (2012) elaboraram geleia de casca de maracujá para reaproveitar o resíduo e verificaram aceitação para todos os atributos avaliados com pontuação acima de $70 \%$, indicando que este tem boa aceitação pelo consumidor e que a baixa aceitação dos cookies elaborados neste estudo pode ser em decorrência das altas concentrações de farinha de casca de maracujá, fazendose necessários novos experimentos para otimizar o produto e reduzir as concentrações para abaixo de $25 \%$, uma vez que esta é mais aceitável pelos provadores.

\section{CONCLUSÕES}

O uso da farinha de casca de maracujá é viável na elaboração de cookies integrais pois apresenta resultados promissores.

A formulação 1 proporciona maior aceitação, entretanto quando adicionado a farinha da casca de maracujá, a formulação 2 obtém maior aceitação em todos os tributos. Necessita-se trabalhos futuros para padronizar a melhor concentração a partir de valores próximos e/ou inferiores a $25 \%$ do produto.

\section{REFERÊNCIAS}

AMARAL. D. A.; PEREIRA, M. L.S.; FERREIRA, C. C.; GREGÓRIO, E. L. Análise sensorial de geleia de polpa de casca de maracujá. Revista HU, v. 38, n. 2, p. 4550, 2012.

ANDO, N.; POSTAL, C.; COUTINHO, R. M. Elaboração de cookie diet com farinha de casca de maracujá-amarelo. XVI Encontro Anual de Iniciação Científica (PIBIC/CNPq). Anais... Universidade Estadual do Centro-Oeste, Guarapuava, PR. 2007.

CÓRDOVA, K. R. V.; BEZERRA, J. R. M. V.; NETO, G. K.; MASSON, M. L.; WASZYCZYNSKY, N. Determinação das Características Físico-Químicas e Sensoriais de Sucos Concentrados de Maracujá. Revista Ciências Exatas e Naturais. v.10, n.2, p. 191-199, 2008

CRUZ, C.; RIBEIRO, U. Metodologia Científica, Teoria e Prática. $2^{\circ}$ ed. Rio de Janeiro: Axcel Books, 2004. 324p.

FERRARI, R.A.; COLUSSI, F.; AYUB, R.A. Caracterização de subprodutos da industrialização do maracujá - Aproveitamento das Sementes. Revista Brasileira de Fruticultura, v.26, n.1, p.101-102, 2004. 
FILHO, G. C. N.; RONCATTO, G.; RUGGIERO, C.; OLIVEIRA, J. C.; MALHEIROS, E. B. Desenvolvimento e Produção das Plantas de Maracujazeiro-Amarelo Produzidas Por Enxertia Hipocotiledonar Sobre Seis Porta-Enxertos. Revista Brasileira de Fruticultura, v.32, n.2, p.527-534, 2010.

HORN, D. S. Dicas Nutricionais - Propriedades Nutricionais do Maracujá, 14 de março de 2014. Disponível em: <http://www.nutricaoeacao.com.br/propriedadesnutricionais-do-maracuja/>. Acessado em: 06/05/2015.

ISHIMOTO, F. Y.; HARADA, A. I.; BRANCO, I. G.; CONCEIÇÃO, W. A. S.; COUTINHO, M. R. Aproveitamento alternativo da casca do maracujá-amarelo (Passiflora edulis f. var. flavicarpa Deg.) para produção de biscoitos. Revista Ciências Exatas e Naturais, v. 9, n. 2, p. 279-292, 2007.

MACAGNAN, F.T. Potencial Tecnológico e Nutricional de Subprodutos do Processamento de Frutas. Santa Maria, RS, Brasil 2013.

OLIVEIRA, L. F.; NASCIMENTO, M. R. F.; BORGES, S. V.; RIBEIRO, P. C. N.; RUBACH, V. R.; Aproveitamento alternativo da casca do maracujá-amarelo (Passiflora edulis F.Flavicarpa) para produção de doce em calda. Ciência e Tecnologia de Alimentos, v.22, n.3, p.259-262, 2002.

SANTOS, A. M. S; Formulação de biscoito tipo cookie a partir da substituição percentual de farinha de trigo por farinha de casca de abóbora (curcubita maxima) e albedo de maracujá amarelo (Passiflora edulis flavicarpa). 2013. $76 f$. Dissertação (Mestrado em Alimentos e Nutrição) - Universidade Federal do Estado do Rio de Janeiro, Rio de Janeiro, 2013.

SANZONOWICZ, C; JUNQUEIRA, N.T.V. Calagem e Adubação do Maracujazeirodoce. Planaltina, DF. Embrapa Cerrado 2005.

ZERAIK, M. L.; PEREIRA, C. A. M.; ZUIN, V.G.; YARIWAKE, J. H. Maracujá: um alimento funcional? Revista Brasileira de Farmacognosia. v.20, n.3, p.459$471,2010$. 